\title{
LUT
}

Lappeenranta

University of Technology

\section{Russian Mechanism to Support Renewable Energy Investments: Before and After Analysis}

Kozlova Mariia, Collan Mikael, Luukka Pasi

This is a Pre-print version of an article

published by Springer

in Computational Methods and Models for Transport - New Challenges to the Greening of Transport Systems

DOI: $10.1007 / 978-3-319-54490-8 \_15$

Copyright of the original publication: (๑) Springer 2017

Please cite the publication as follows:

Kozlova, M., Collan, M., Luukka, P. (2017). Russian Mechanism to Support Renewable Energy Investments: Before and After Analysis. Computational Methods and Models for Transport.

Computational Methods in Applied Sciences. p. 243-252. DOI: 10.1007/978-3-319-54490-8_15

This is a parallel published version of an original article. This version can differ from the original published article. 


\title{
Russian Mechanism to Support Renewable Energy Investments: Before and After Analysis
}

\author{
Mariia Kozlova, Mikael Collan, and Pasi Luukka \\ Lappeenranta University of Technology, School of Business and Management \\ BOX 20, 53851 Lappeenranta, Finland \\ mariia.kozlova; mikael.collan; pasi.luukka; @lut.fi
}

\begin{abstract}
This chapter presents an analysis of how the new Russian support policy for renewable energy investments changes the expected profitability of renewable energy investments in Russia. A comparative analysis of investment profitability in the before and after support policy cases is presented for a wind farm investment to illustrate the effect of the policy. This chapter is among the first reported research to comparatively analyze the effect of the Russian renewable energy support mechanism on investment project profitability.
\end{abstract}

Keywords: Renewable energy, real option, policy effect, Russia

\section{Introduction}

To ensure strategic investments in emerging technologies such as renewable energy (RE) that cannot at this time compete with conventional solutions in industrial scale in terms of profitability, policymakers may introduce support mechanisms. The design of support mechanisms has turned out to be crucial in being able to incentivize the deployment of the target RE technologies into the energy markets. This is due to the maturity level of the present day technology - RE power projects are typically not profitable without policy support. It remains to be seen how fast the development of technology is able to change the situation. Ideally, a supporting policy for RE should serve multiple goals, such as the reduction of the risks of investment, to provide motivation to invest cost efficiently, and be feasible from the point of the society that is paying for the bill. Typically, the main RE support policy types used include a remuneration scheme that guarantees an investor supplemental income to guarantee profitability, if an investment fulfills given criteria. The level of the supplemental income can be defined in different ways and common ways to do this include, e.g., using a special price to be paid for electricity produced by RE investments (feed-in tariffs), exploring the minimum acceptable electricity price through competitive 
auctions, and letting the markets define the price by establishment of RE certificate trade, which RE producers receive for their production (REN21, 2015).

In this chapter we concentrate on studying the Russian RE support mechanism for the wholesale energy market. Under the present day conditions, industrial-scale renewable energy production investments in Russia are seldom considered as a relevant option without the support mechanism and would be deemed "universally" unprofitable without one. The focus of this chapter is to study the effect the Russian renewable energy (RE) incentive mechanism has on the profitability of Russian RE investments. The analysis presented is based on the codified details of the Russian RE mechanism and its pricing instructions that available in the original Russian language legislative procedures (Russian law) (Government of Russian Federation, 2013a; Government of Russian Federation, 2013b; Government of Russian Federation, 2015) and in a policy report (International Finance Corporation, 2013). Most likely it is due to the lack of English language sources on the Russian RE policy that it has received relatively little attention in the academic literature.

Previous literature that studies the Russian RE policy includes a qualitative study of the draft version of policy (Boute, 2012), an analysis of its impact on the Russian electricity and capacity prices (Vasileva, Viljainen, Sulamaa, \& Kuleshov, 2015), and a number of investigations concerning RE investment profitability in Russia (Kozlova, Collan, \& Luukka, 2015; Kozlova, 2015; Kozlova \& Collan, 2015). To the best of our knowledge, a comparative "before - after" study of the effect of the Russian RE policy to RE investments in Russia has not been presented. It is here that we aim to make a contribution by analyzing this effect.

We use a previously presented (Kozlova, 2015) system dynamic investment model as a basis for a simulation analysis to study the profitability of a wind farm investment in Russia with and without the supporting policy. The results show that there is significant effect to project profitability.

This chapter continues by shortly presenting the Russian support mechanism for renewable energy, then a simulation analysis of the profitability of a stylized wind farm investment case is made, ceteris paribus, with and without the supporting policy in place, and finally the paper is closed with a discussion and conclusions are drawn. 


\section{Russian capacity market and the support mechanism for RE investments}

Russian capacity mechanism for renewable energy support is an extension to the pre-existing Russian national capacity trade principles. The Russian power market consists of a capacity market that operates alongside the electricity market (Gore, Viljainen, Makkonen, \& Kuleshov, 2012). The idea behind capacity trade is to assure ability of a power system to meet electricity demand in the long term by timely incentivizing investments in new power plants. Selling capacity means getting paid for being available to produce electricity (Olsina, Pringles, Larisson, \& Garcés, 2014).

The Russian capacity market is organized through competitive capacity selection that is carried out by the centralized infrastructure organization System Operator (SO), where existing power generators submit their bids with available volumes of installed capacity for a pre-specified period (NP Market Council, 2012). In addition, new planned projects compete for long-term capacity delivery agreements with regulated price (Boute, 2012). Capacity power generators that have won contracts are obliged to follow dispatching orders from the SO that enable the management of the power system operation. On the demand side, each electricity buyer in the wholesale market is obliged to buy capacity according to the buyer's peak demand. The price of capacity is defined as a weighted average of contracted and auctioned capacity prices that include the "winning bids" of auctions and the regulated tariffs of long-term capacity delivery agreements (Gore \& Viljainen, 2014). Notably, the procedure of capacity price calculation for the long-term agreements is designed to assure a riskless return on each investment project. This mechanism is taken as a foundation for designing the remuneration scheme for renewable energy support.

In May 2013, the Government of Russian Federation presented an extended capacity mechanism that is specific to RE power generation, with the aim to support the deployment of almost $6 \mathrm{GW}$ of new renewable energy capacity by the year 2020 (Government of Russian Federation, 2013a; Government of Russian Federation, 2013b). Once a year, competitive capacity auctions are conducted for investment projects into wind, solar PV, and small $(<25$ MW) hydropower. The selection of projects is carried out for a four-years-ahead commercialization window and is based on (i) compliance to participation requirements and on (ii) the least planned capital costs criterion. There is a set yearly target installed capacity volume for each particular RE technology, up to which projects are selected. The participation requirements include a technology-specific capital expenditure limit and a 
requirement to procure a share of the used equipment from local Russian manufacturers (local content) (International Finance Corporation, 2013).

The selected projects are eligible for a long-term capacity delivery agreement that allows them to benefit from monthly capacity payments for fifteen years, starting from these projects' commercialization date. The capacity agreement comes into force only after a qualification procedure after the construction end in accordance with (Government of Russian Federation, 2008). The procedure registers a power plant as one operating on a renewable energy source and controls and confirms the fulfillment of the local content requirement. The policy obliges the winning RE projects to start operations on time and penalizes for delays, while the obligation that in place for "conventional energy production" facilities to follow dispatching orders is "softened" to the requirement of complying with SO orders to switch off electricity production (Government of Russian Federation, 2013a).

The RE capacity price calculation is centralized and the procedure is designed to guarantee a specific return on investment regardless of the changing market conditions. The guaranteed return is defined as $12 \%$ annually corrected by changes in market interest rates (or $15 \%$ for projects auctioned before 1.01.2016). The market interest rates are represented by long-term Russian government bond yield. The capacity payments are designed to cover project costs and to provide some return over it. The estimated project costs comprise of capital expenditures (CapEx), operating expenses (OpEx), and of taxes. The capital expenditures are directly taken from the submitted bid information and are project-specific. They are converted into monthly payments. The 'foreign' share of the capital costs is translated to rubles during the project investment phase. For operating expenses the mechanism sets technology-specific norms that are corrected with inflation, which is incorporated into the calculation by using the consumer price index as a proxy. Project-specific property tax forecast, based on planned capital costs and a 20\% income tax are included in the estimated project expenses for capacity price calculation.

The complex calculation of the capacity payments introduces a complicated "effect" that influences project profitability analysis. The key market and project-internal factors directly affect project profitability, while they also enter in the capacity price payment computations and create "cross-effects" on project profitability (see Figure 1). It can be understood that the procedure is rather complex. For details we refer the interested reader to study Appendix 1. 


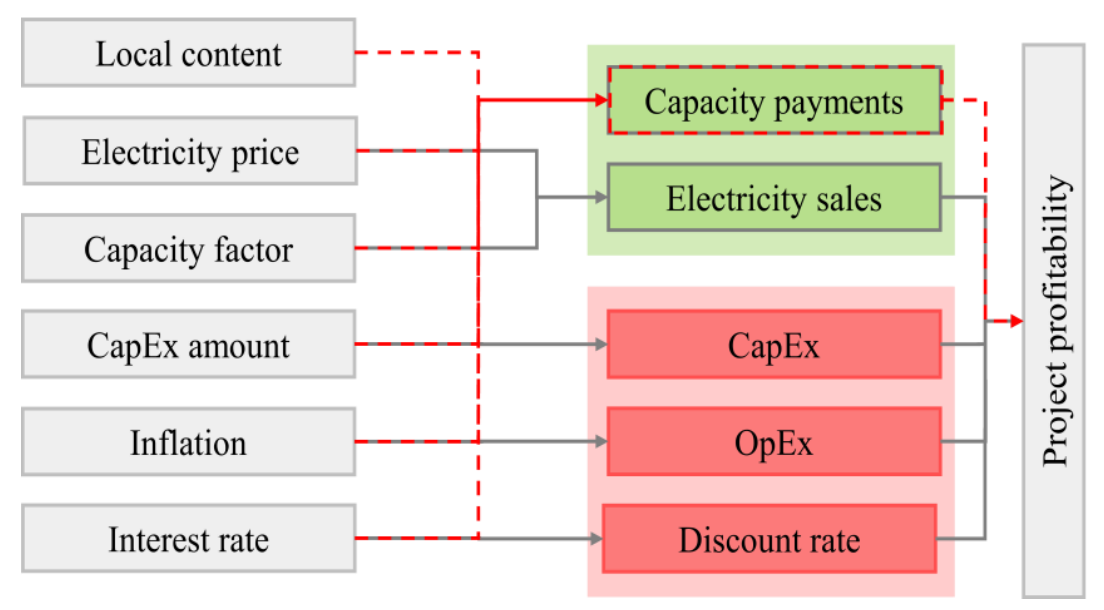

Figure 1. The factors affecting Russian RE investment profitability

Capacity sales are not the only source of revenues for a power plant project, there is also income from the electricity sales. This is why the capacity payments do not cover all the estimated project costs, but only the share of costs that is computed via an analysis of an average project. This share of expenses is also a subject to annual recalculation, based on changing electricity prices and changes in other conditions. (Government of Russian Federation, 2013a; Government of Russian Federation, 2015).

The mechanism uses several ways to shape investor motivation to invest in RE projects, typically non-conformity with requirements decreases the support received, such cases include situations where, the plant qualification procedure reveals that the local content requirement is not fulfilled and where the volume of the yearly produced electricity is too low.

To summarize, the RE capacity price is calculated for each project on an annual basis and the aim is to provide a riskless return on the RE investment. The capacity price is adjusted based on the changing market conditions that include interest rates, electricity prices, inflation, and exchange rates. Project-specific factors such as capital costs, local content, and electricity production performance are taken into account. More detailed information about the policy and the capacity pricing can be found in (Boute, 2012; International Finance Corporation, 2013; Kozlova, 2015) and from the original Russian legislation (Government of Russian Federation, 2013a; Government of Russian Federation, 2013b; Government of Russian Federation, 2015). 
In the following section of this chapter we present a case and a numerical illustration that uncovers the effect of the Russian RE support mechanism on the profitability of a wind farm investment.

\section{Case: effect of the Russian RE support mechanism on a wind farm investment profitability}

The analysis presented is based on the use of a system dynamic model built to study the profitability of a stylized wind farm investment. The model used has been presented in detail in (Kozlova, 2015). The model realized with Matlab Simulink®, is built to fully represent the details of the Russian RE support mechanism, and the profitability calculation part of the model is based on using a typical discounted cash-flow logic that returns the project NPV as a result. The model is used as the basis for a Monte Carlo simulation (Hacura, JadamusHacura, \& Kocot, 2001; Kwak \& Ingall, 2007). The simulated NPV results are presented as histograms.

We have chosen a $10 \mathrm{MW}$ wind farm as the case to be studied, solar PV and small hydropower projects generate very similar results. The wind farm is assumed to be commissioned in 2017, and to start generating cash-flows immediately thereafter for the next 20 years. In the base case investment the total capital costs are assumed to be equal to cost level set by the Russian legislation limit of 110 Mrub./MW. The operating costs are assumed to be equal to the normative $188 \mathrm{Krub}$./MW per month, adjusted with inflation. We assume inflation to be an uncertain variable and assume it to stay within a range of 1 to 1.7 , in terms of consumer price index. The revenues are treated as uncertain and they are modeled to consist of electricity sales with uncertain price that are assumed to range from 1 to 3 rub./kWh (corresponding to typical prices on the markets), by a capacity factor that is equal to the target, and the capacity payments that are calculated according to the support mechanism procedure. Values of the uncertain variables are expected to have a uniform distribution, except for the "local content" variable that is binary and may only take the value zero or one. The Russian risk-free rate used in all calculations is assumed to be fixed at ten percent - its effects are studied separately.

Three simulation runs are performed with the model, one without the support policy (run A), one with the support policy (run B), and a third one to illustrate the situation, where a project is able to completely fulfill the requirements of the support policy and thus being able to 
enjoy the full benefits of the said policy (run C). Each simulation run consisted of 100,000 simulation rounds. Details for the three simulation runs are visible in Table 1.

Table 1. Summary of the parameter values and settings for the simulation runs

\begin{tabular}{|l||l|l|l|l|l|l|}
\hline Run & Policy & $\begin{array}{l}\text { CapEx (of the } \\
\text { limit 110 } \\
\text { Mrub./MW) }\end{array}$ & $\begin{array}{l}\text { Capacity factor } \\
\text { (from target } \\
27 \%)\end{array}$ & $\begin{array}{l}\text { Local } \\
\text { content }\end{array}$ & $\begin{array}{l}\text { Electricity } \\
\text { price }\end{array}$ & $\begin{array}{l}\text { Consumer } \\
\text { price index }\end{array}$ \\
\hline \hline A & $\begin{array}{l}\text { Not in } \\
\text { place }\end{array}$ & $\begin{array}{l}\text { Uncertain } \\
100 \%-150 \%\end{array}$ & $\begin{array}{l}\text { Uncertain } \\
30 \%-100 \%\end{array}$ & - & $\begin{array}{l}\text { Uncertain } \\
1-3 \\
\text { rub./kWh }\end{array}$ & $\begin{array}{l}\text { Uncertain } \\
1-1.7\end{array}$ \\
\hline B & $\begin{array}{l}\text { In } \\
\text { place }\end{array}$ & $\begin{array}{l}\text { Uncertain } \\
100 \%-150 \%\end{array}$ & $\begin{array}{l}\text { Uncertain } \\
30 \%-100 \%\end{array}$ & Uncertain & $\begin{array}{l}\text { Uncertain } \\
1-3 \\
\text { rub./kWh }\end{array}$ & $\begin{array}{l}\text { Uncertain } \\
1-1.7\end{array}$ \\
\hline C & $\begin{array}{l}\text { In } \\
\text { place }\end{array}$ & Certain 100\% & $\begin{array}{l}\text { High } \\
90 \%-100 \%\end{array}$ & Fulfilled & $\begin{array}{l}\text { Uncertain } \\
1-3 \\
\text { rub./kWh }\end{array}$ & $\begin{array}{l}\text { Uncertain } \\
1-1.7\end{array}$ \\
\hline
\end{tabular}


Market uncertainty represented in the model by electricity prices and inflation is modeled equally through the all three runs. The run A represents no policy situation, thus the project receives no capacity payments and benefits only from electricity sales. We assume possibility of CapEx increase to a maximum of $150 \%$ of the basic value of 110 Mrub./MW. The capacity factor used in the RE support mechanism depends on resource availability and we assume it to vary within a broad range from $30 \%$ to $100 \%$ of the target capacity factor that is equal to $27 \%$ for wind power.

The difference in run A without the supporting policy in place and run B, where the policy is in place, is the appearance of the supporting subsidy payments and the "local content" variable. The local content is typically fulfilled, as the investors most likely will not start project construction if the local content requirement cannot be fulfilled, because this would mean almost certainly that the project is unprofitable.

Run C illustrates the situation when the project is able to comply with all policy requirements and achieves the full support payments without any penalties for underperformance. Figure 2 presents the resulting NPV distributions from the three runs as histograms.
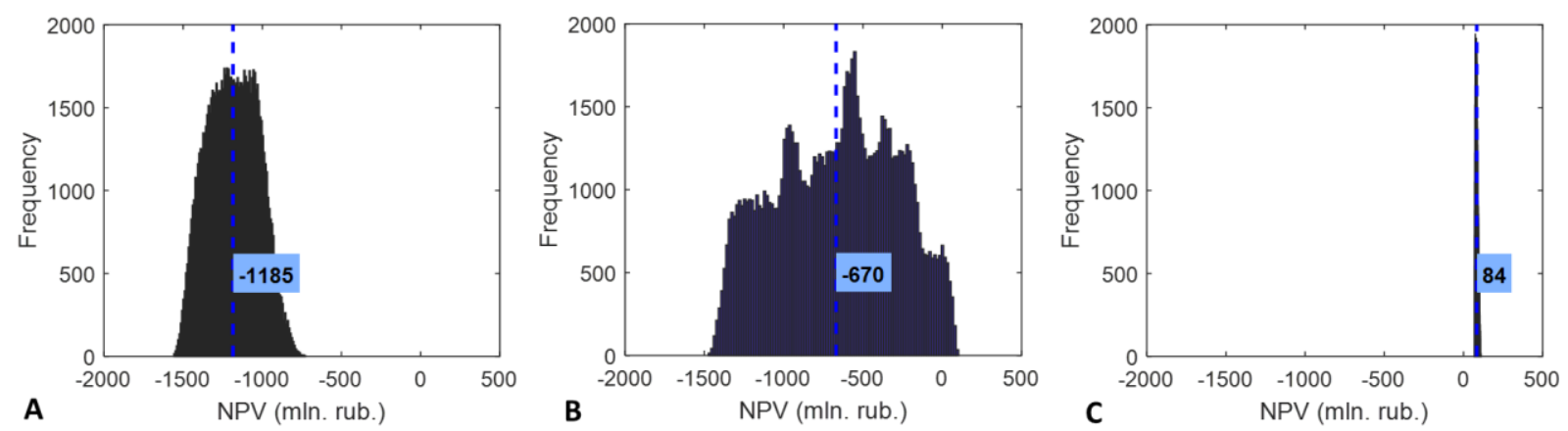

Figure 2. NPV distributions for three scenarios (expected mean highlighted)

We can see from Figure 2 how the introduction of the supporting mechanism changes the NPV distribution of the investment (Figure $2 \mathrm{~A}$ and B). What is important to notice is that the distribution resulting from the "no support mechanism" case (run A) consists of only negative profitability outcomes, while the presence of the supporting mechanism shifts the distribution to the right and creates a possibility for profitable investment.

Results from run A are realistic in the sense that industrial-scale RE investments have not been profitable in Russia without support. The distribution that results from run B has a multi-peak shape that is caused by complex rules behind the support mechanism that determines the capacity remuneration paid to the investment under different circumstances. 
The lower bound of the distribution remains the same in both cases, because in case of poor project performance also a project "under" the support mechanism remains without any support.

The difference between the two distributions can be simply calculated as the difference between the mean NPV values of runs A and B, which amounts to 515 million rubles for the investment project or more generally 52 million rubles per $1 \mathrm{MW}$ of wind power installed capacity. This can also be interpreted as a real option value that is generated by the support mechanism. Comparing the means may not be very useful while both are negative, therefore we have also separately studied the situation of a project that is able to fulfill all the requirements of the support policy (run C).

The resulting distribution from run $\mathrm{C}$ is very concentrated and entirely in the positive area. This means that under the studied conditions a project that is able to fulfill all the set requirements of the support policy is able to guarantee positive NPV with a small variation of outcomes even in the presence of the uncertain market factors. This highlights the fact that it makes sense for the investors to be proactive in pushing their performance to fulfill the requirements of the policy. This is also in line with the policy objectives. For such projects the value of the support policy, in comparison to the preceding situation without the policy, is quite remarkable and stands at 1269 million rubles, or 127 million rubles per MW. This can be considered a real option value.

The Russian RE capacity mechanism shields investors not only from the price risk, but also from the interest rate risk. Therefore, the effects of changing interest rates on the project profitability require separate attention. The capacity price is computed as an annuity with variable rate that is adjusted to the changes in the local risk-free rate. Thus, an increase in the risk-free rate leads to higher capacity payments, and consequently to a higher internal rate of return of the project. Technically speaking, without such mechanism in place the higher interest rates would reduce the NPV due to higher discount rates. The design of Russian RE support offsets this reduction effect by offering an increased capacity price when interest rates rise and aims to keep project profitability on the same level. This feature is designed to enable investors to cope with higher costs of financing without harming the project profitability. 
A numerical sensitivity analysis performed of the effect of the Russian risk-free rate to the project profitability shows that there is a close to linear positive relationship between the project IRR and the risk-free rate arising from the remuneration design, see Figure 3.

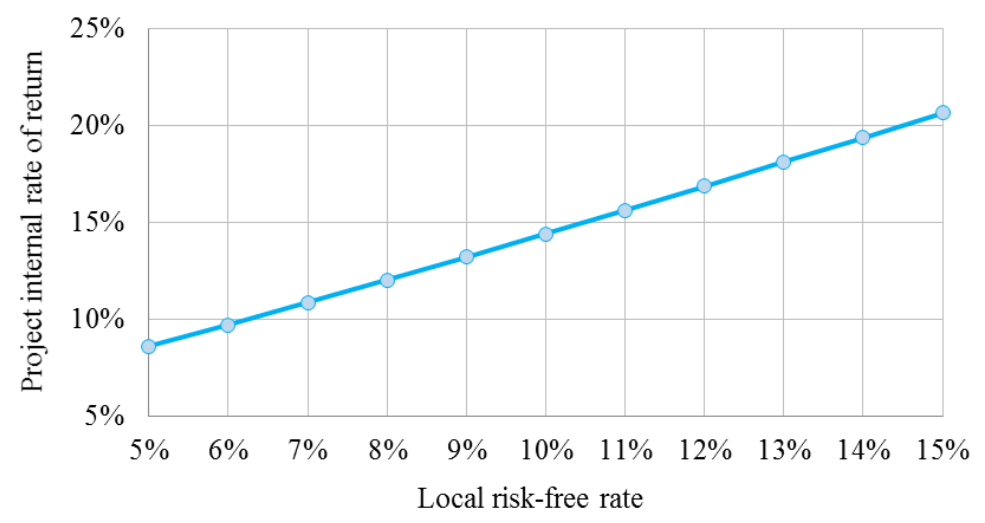

Figure 3. Sensitivity of project internal rate of return (IRR) to the Russian risk-free rate under the support policy

This is a non-insignificant analysis in the Russian context, where the risk-free rate may experience considerable changes over time. What is interesting and important to note is that the choice of contract in terms of floating or fixed interest on the project debt plays a role in project profitability: change in the interest rate of a floating rate loan is most likely offset by the support mechanism to a large extent.

In general, the results show that the Russian RE support mechanism is able to provide higher profitability to $\mathrm{RE}$ projects and projects that are able to consistently fulfill the set requirements may enjoy a situation of low risk profitability. This also means that investors should proactively try to steer their investments into meeting the set criteria.

\section{Discussion and conclusions}

In this chapter we showed how the Russian renewable energy support mechanism works and how it changes the profitability outlook of RE power investments in Russia. The Russian RE support mechanism is unique in terms of its construct, which is rather complex. The mechanism aims to guarantee profitability for investments that fulfill the set criteria by offering capacity payments to RE investments. The capacity pricing mechanism that determines the size of the payments starts by defining the required return on investment and then uses it to compute a remuneration amount needed for a particular project to achieve this return. This remuneration is a subject to yearly recalculations in that take into account the changing market environment and the project performance in the long-term. As the result, the 
mechanism allows investors a lower risk with regards to the project profitability and allows them to enjoy a greater level of independence from Russian market conditions if they comply with set policy requirements. Real world results from the implementation of the said policy so far suggest that the support mechanism is able to provide sufficient incentive for investors for investment in solar power. Experience with wind and small hydropower shows that the selection of parameter values for the support mechanism needs more work with regards to these technologies.

We demonstrated with a system dynamic model of a wind power generation investment how the Russian RE support mechanism changes the profitability landscape of the investment there is a significant and an important effect that allows projects that fulfill the set policy requirements to be profitable. This chapter is among the first, if not the first, to comparatively analyze the effect of the Russian support mechanism on the profitability of renewable energy investments in Russia.

Further research into this topic will include comparing the results with results from using other commonly used RE support mechanisms.

\section{References}

1. Boute, A. (2012). Promoting renewable energy through capacity markets: An analysis of the Russian support scheme. Energy Policy, 46(0), 68-77.

2. Gore, O., \& Viljainen, S. (2014). Challenges of cross-border trade between two markets with different designs. European Energy Market (EEM), 2014 11th International Conference on The, pp. 1-5.

3. Gore, O., Viljainen, S., Makkonen, M., \& Kuleshov, D. (2012). Russian electricity market reform: Deregulation or re-regulation? Energy Policy, 41(0), 676-685.

4. 3 June 2008 Decree \#426 on the Qualification of Renewable Energy Sources Installations, (2008).

5. 28 may 2013 Decree \#449 on the Mechanism of Promoting the use of Renewable Energy in the Wholesale Market of Electric Energy and Power, (2013a).

6. 28 may 2013 Resolution \#861-R on Amendments being made to Resolution \#1-R 8.01.2009 on the Main Directions for the State Policy to Improve the Energy Efficiency of the Electricity Sector on the Basis of Renewable Energy Sources for the Period Up to 2020, (2013b). 
7. 10 November 2015 Decree \#1210 on the Introduction Of amendments to the Certain Legislative Acts regarding the use of Renewable Energy Sources in The wholesale electricity and Capacity Market, (2015).

8. Hacura, A., Jadamus-Hacura, M., \& Kocot, A. (2001). Risk analysis in investment appraisal based on the Monte Carlo simulation technique. The European Physical Journal B-Condensed Matter and Complex Systems, 20(4), 551-553.

9. International Finance Corporation. (2013). Russia's new capacity-based renewable energy support scheme. an analysis of decree no. 449. Retrieved October 6, 2015, from http://www.ifc.org/wps/wcm/connect/f818b00042a762138b17af0dc33b630b/EnergySuppor-Scheme-Eng.pdf?MOD=AJPERES

10. Kozlova, M., Collan, M., \& Luukka, P. (2015). Renewable energy in emerging economies: Shortly analyzing the Russian incentive mechanisms for renewable energy investments. International Research Conference "GSOM Emerging Markets Conference-2015: Business and Government Perspectives”, Saint-Petersburg, Russia.

11. Kozlova, M. (2015). Analyzing the effects of the new renewable energy policy in Russia on investments into wind, solar and small hydro power. (Master's thesis, Lappeenranta University of Technology)., 104.

12. Kozlova, M., \& Collan, M. (2015). Financing renewable energy projects in Russia under new legislation. Renewable Energy Sources: The Collection of Lectures, (8) pp. 270278.

13. Kwak, Y. H., \& Ingall, L. (2007). Exploring Monte Carlo simulation applications for project management. Risk Management, 9(1), 44-57.

14. NP Market Council. (2012). Wholesale market. Retrieved March 12, 2016, from http://www.en.npsr.ru/abouttheelectricityindustry/electricityandcapacitymarkets/wholesalemarket/\#3

15. Olsina, F., Pringles, R., Larisson, C., \& Garcés, F. (2014). Reliability payments to generation capacity in electricity markets. Energy Policy, 73(0), 211-224.

16. REN21. (2015). Renewables 2015 global status report. Retrieved August 15, 2015, from http://www.ren21.net/wp-content/uploads/2015/07/REN12GSR2015_Onlinebook_low1.pdf

17. Vasileva, E., Viljainen, S., Sulamaa, P., \& Kuleshov, D. (2015). RES support in Russia: Impact on capacity and electricity market prices. Renewable Energy, 76(0), 82-90. 


\section{Appendix 1. The RE capacity price calculation procedure}

Russian RE capacity price calculation procedure is presented in accordance with (Government of Russian Federation, 2013a) and divided into four consecutive steps: (i) rate of return, (ii) share of expenses to be covered by capacity payments, (iii) capacity price component, and (iv) capacity price.

1. Rate of return $R i$ is defined as required rate $R r$ equal to $12 \%$ corrected on change in the local risk-free rate $R_{f_{i}}$ relative to the initial local risk-free rate $R_{f_{0}}$ set at $8.5 \%$.

$$
R_{i}=\frac{\left(1+R_{r}\right) *\left(1+R_{f_{i}}\right)}{\left(1+R_{f_{0}}\right)}-1 \approx R_{r}+\Delta_{R_{b}}
$$

2. Preliminary expense share $E$ is determined for an average RE power generator technology wise by relating expected revenue from electricity sales $R e$ to expected revenue from capacity sales $R c$.

$$
E_{i}=\frac{R e_{i}}{12 * R c_{i}}
$$

Expected revenue from capacity sales $R c$ is determined in accordance with the next third step with following assumptions: expense share is equal to 1 and capital costs (CapEx) are defined as weighted average of CapEx of bids submitted to the corresponding auction (technology wise). Hence, step 3 is repeated twice: firstly, for an 'average project' to determine the expense share, and secondly, to calculate actual capacity price for a particular project.

Revenue from electricity sales $R e$ is defined as follows:

$$
R e_{i}=c f_{i} * \text { hours } *\left(\frac{P_{i}}{k_{e n}}-C_{p r_{i}}\right) \text {, }
$$

where

$c f$ is a normative capacity factor $(27 \%, 14 \%$, and $38 \%$ for wind, solar PV and small hydro power respectively);

hours is an amount of hours in year $i$;

$P$ is a day ahead electricity market price defined later;

$k_{e n}$ is a coefficient of power consumption for own needs that is 1.005 for all RE types;

$C p r$ is inflated cost of production initially defined for wind, solar, and hydro as 1,1 , and 10 rub/MWh correspondingly. 
Day ahead electricity market price is forecasted for each group of provisional supply points as a weighted average prices through the whole previous year corrected on the growth rate using the following formula:

$$
P_{i}=\frac{\sum_{h} \sum_{q} P_{q, h} * \operatorname{Prod}_{q, h}}{\sum_{h} \sum_{q} \operatorname{Prod}_{q, h}} * \prod_{Y=X}^{i} g_{Y}^{C},
$$

where

$h$ is an hour of previous year;

$q$ is a group of provisional supply points;

$P_{q, h}$ is day ahead electricity price for a particular group of supply points and a particular hour;

$\operatorname{Prod}_{q, h}$ is production volume for a particular group of supply points and a particular hour;

$g^{C}{ }_{Y}$ is a forecasted growth rate of prices of gas (for the first price zone) or of coal (for the second price zone) for year $Y$.

To determine final expense share, firstly, average of the same and next year preliminary expense share is calculated, then, expense share for uneven years of contract duration equals to this average and for even years to the value of the calculated expense share for the previous year.

3. Capacity price component consists of CapEx converted to annuity payments and operating expenses (OpEx). Firstly, adjusted capital expenses CapExadj are calculated by applying to declared planned amount of CapEx, CapEx $x_{\text {plan }}$, localization coefficient $k_{\text {local }}$, coefficient that reflects revenues after contract expiration $k_{\text {exp }}$, and coefficient that corrects the 'foreign' part of the CapEx to change in the exchange rates $k_{\text {exch }}$, multiplying it by the expense share calculated in the step 2 and by the rate factor for the year preceding the first year of the contract $R_{-1}$.

$$
\operatorname{CapEx}_{a d j}=\operatorname{CapEx}_{\text {plan }} * k_{\text {local }} * k_{\text {exp }} * k_{\text {exch }} * E *\left(1+R_{-1}\right)
$$

Then adjusted CapEx is converted to the annuity payments with variable interest rate. Principal payment and remaining principal are defined as follows (principal implies adjusted CapEx):

$$
\begin{gathered}
P p_{i}=\frac{R p_{i} * R_{i-1}}{\left(\left(R_{i-1}+1\right)^{16-\mathrm{i}}-1\right)}, \\
R p_{i}=R p_{i-1}-P p_{i-1}+\left(R_{i-1}-R_{i-2}\right) *\left(1+R_{i-1}\right) * R p_{i-1},
\end{gathered}
$$


where $P p_{i}$ is principal payment;

$R$ is the variable rate defined in the step 1 ;

$R p_{i}$ is a remaining principal, for $i=1$ and $R_{l}=C a p E x_{a d j}$.

Capacity price component $C P_{\text {comp }}$ is defined as a sum of interest payment on before-tax principle and principle payment converted to monthly terms, and inflation adjusted operating expenses $O p E x$ multiplied on the expense share:

$$
C P_{\text {comp }}=\frac{R p_{i} * \frac{R_{i-1}}{1-r_{i n c_{\text {tax }}}}+P p_{i}}{12}+O p E x * E,
$$

where rinctax is an income tax rate equal to 0.2 ;

$O p E x$ is an inflation adjusted (since 2012) OpEx norm (118, 170 and 100 rub./kW per month for wind, solar PV and hydro power respectively).

4. Finally, capacity price $C P$ is defined as a sum of capacity price component $C P_{\text {comp }}$ calculated in the previous step and property tax expenses $T_{p r}$ multiplied by the expense share $E$, corrected on the fixed coefficient of energy for own needs $k_{\text {en }}$ equal to 1.005 for all types of RE and on load coefficient $k_{\text {load: }}$

$$
\begin{gathered}
C P=\left(C P_{\text {comp }}+\frac{T_{p r}}{12} * E\right) * k_{\text {en }} * k_{\text {load }} \\
k_{\text {load }}=\left\{\begin{array}{c}
1, c f_{\text {fact }}>0.75 * c f_{\text {target }} \\
0.8,0.5 * c f_{\text {target }}<c f_{\text {fact }} \leq 0.75 * c f_{\text {target }} \\
0, c f_{\text {fact }} \leq 0.5 * c f_{\text {target }}
\end{array}\right.
\end{gathered}
$$

where

$c f_{\text {fact }}$ is previous year factual capacity factor;

$c f_{\text {target }}$ is the target capacity factor set by the legislation. 